\title{
Exceptionally Stable Microporous Organic Frameworks with Rigid Building Units for Efficient Small Gas Adsorption and Separation
}

Weiqiu Wen ${ }^{\dagger}$, Peter S. Shuttleworth ${ }^{*}$, Hangbo Yue ${ }^{*}{ }^{\dagger}$, Juan P. Fernández-Blázquez ${ }^{\S}$, and Jianwei Guo *广

${ }^{\dagger}$ School of Chemical Engineering \& Light Industry, Guangdong University of Technology, Guangzhou 510006, China.

${ }^{\star}$ Department of Polymer Physics, Elastomers and Energy, Institute of Polymer Science and Technology, CSIC, 28006 Madrid, Spain.

${ }^{\S}$ IMDEA Materials Institute, Eric Kandel 2, Getafe, Madrid 28906, Spain.

*Corresponding Author

E-mail: hangbo.yue@gdut.edu.cn (H.Y), guojw@gdut.edu.cn (J.G). 


\section{Table of contents}

Detailed synthesis methods. 3

Solid-state ${ }^{13} \mathrm{C}$ NMR spectra assignment of MPOF-Ads networks ........................... 7

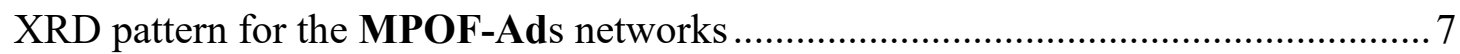

FTIR spectra of the as-synthesized MPOF-Ads networks compared to that had been

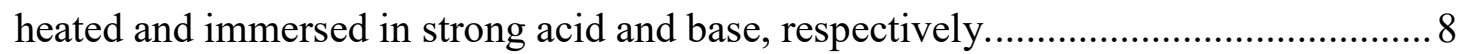

$\mathrm{CH}_{4}$ Adsorption isotherms for the MPOF-Ads networks ...................................... 10

$\mathrm{N}_{2}$ Adsorption isotherms for the MPOF-Ads networks ......................................... 10

Calculations forisosteric heat of adsorption $\left(\mathrm{Q}_{\mathrm{st}}\right)$ of MPOF-Ads networks................. 10

Initial slope selectivity studies for MPOF-Ads networks ...................................... 11

Calculations for selectivites of $\mathrm{CO}_{2} / \mathrm{CH}_{4}$ and $\mathrm{CO}_{2} / \mathrm{N}_{2}$ gas mixtures by Ideal Adsorption

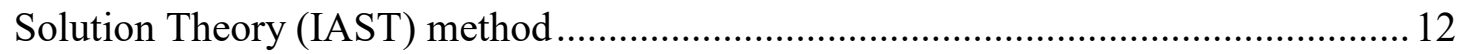

Comparison of the gas uptake capablities of MPOF-Ads networks with literature

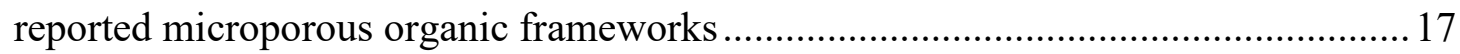

Computational details and corresponding results .................................................. 18

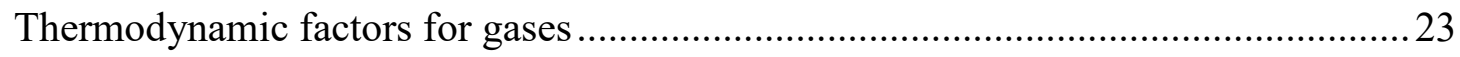

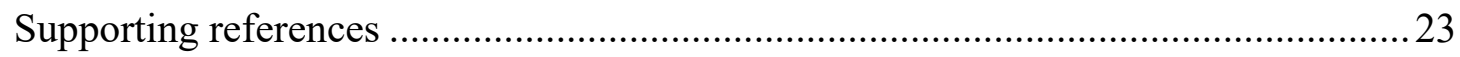




\section{Detailed synthesis methods.}

\subsection{1,3,5,7-Tetrakis(4-iodophenyl)adamantane (TIPA): Iodine (4.72 g, $18.16 \mathrm{mmol})$}

was added to a suspension of 1,3,5,7-tetraphenyladamantane $(4.0 \mathrm{~g}, 9.08 \mathrm{mmol})$ in cholroform (50 ml) and the mixture was stirred until the iodine had dissolved. Then, (bis(trifluoroacetoxy)iodo)benzene $(7.8 \mathrm{~g}, 18.16 \mathrm{mmol}$ ) was added and the suspension was stirred for $24 \mathrm{~h}$ at room temperature. The mixture was filtered to remove a purple solid. The organic layer was washed with saturated aqueous sodium hydrogensulfite solution $(5 \%, 100 \mathrm{ml} \times 3)$, water $(50 \mathrm{ml} \times 3)$, and brine $(50 \mathrm{ml} \times 3)$, and dried over magnesium sulfate. After the organic layer was evaporated under reduced pressure, the pale yellow crude product was obtained and then recrystallized in a chloroform/methanol mixture $(9: 1, \mathrm{~V}: \mathrm{V})$ to isolate colorless crystals of TIPA (4.46 g, $4.72 \mathrm{mmol}, 51.98 \%)$.

1.2 1,3,5,7-Tetrakis(4-ethynylphenyl)adamantane (TEPA): TIPA (4.46 g, 4.74 mmol, 1 equiv) was dissolved in the mixture of dry toluene $(50 \mathrm{ml})$ and TEA $(25 \mathrm{ml})$. Then, TMSA (9.30 g, $94.8 \mathrm{mmol}, 20$ equiv), $\mathrm{Pd}\left(\mathrm{PPh}_{3}\right)_{4}(544.4 \mathrm{mg}, 0.47 \mathrm{~mol}, 10 \mathrm{~mol} \%)$ and CuI (90.3 mg, $0.47 \mathrm{mmol}, 10 \mathrm{~mol} \%)$ was successively added under argon atmosphere. The mixture was heated to $90{ }^{\circ} \mathrm{C}$ and stirred for $48 \mathrm{~h}$. After cooling to ambient temperature, the mixture was filtered to remove all salts including Pd catalyst, and the filtrate was evaporated by reduced pressure. The residue was then taken up in chloroform (200 ml), washed with an aqueous solution of $\mathrm{HCl}(10 \%)$ and water, and dried over magnesium sulfate. The crude 1,3,5,7-tetrakis(4-trimethylsilyl-ethylenphenyl)-adamantane (3.21 g, $3.89 \mathrm{mmol}, 1$ 
equiv) was used for the next reaction (deprotection) without further purification. KF (2.26 g, 38.9 mmol, 10 equiv) was added to a suspension of the silylated product in methanol $(50 \mathrm{ml})$ and stirred overnight at $50{ }^{\circ} \mathrm{C}$. The reaction mixture was was poured into water $(50 \mathrm{ml})$ and extracted with chloroform $(100 \mathrm{ml})$. The organic layer was washed with water $(100 \mathrm{ml} \times 2)$, and brine $(100 \mathrm{ml} \times 2)$. The organic layer was dried over magnesium sulfate, and the solvent was remove in vacuo.

1.3 3,3', 5, 5', 7,7'-hexakis(4-bromophenyl)-1,1'-biadamantane (HBPBA): $\mathrm{Br}_{2}$ (50 ml) and anhydrous $\mathrm{AlCl}_{3}(2.66 \mathrm{~g} 19.96 \mathrm{mmol})$ were fed into a $150 \mathrm{ml}$ three neck round-bottom flask equipped with reflux condenser and stirred slowly for $30 \mathrm{~min}$. Then, 1,1'-Biadamantane $(2.70 \mathrm{~g}, 9.98 \mathrm{mmol})$ was added portionwise under $0{ }^{\circ} \mathrm{C}$ over $30 \mathrm{~min}$, and the flask was slowly heated to $85{ }^{\circ} \mathrm{C}$ and held at that temperature for $48 \mathrm{~h}$. Hydrogen bromide was evolved copiously during the heating. After the reaction, the mixture was allowed to cool down to room temperature and treated subsequently with saturated aqueous $\mathrm{NaHSO}_{3}$ solution. The precipitate was remove by filtration and air dried overnight. The crude product was extracted with $\mathrm{CHCl}_{3}$ for $24 \mathrm{~h}$ and then recrystallized from N-Methyl-2-pyrrolidinone to give a white power, 3,3', 5, 5', 7,7'-Hexabromo-1,1'-boadamantane (HBA).

Bromobenzene $(50 \mathrm{ml})$, anhydrous $\mathrm{FeCl}_{3}(0.01 \mathrm{~mol})$ and $\mathbf{H B A}(0.01 \mathrm{~mol})$ were successively added into a $100 \mathrm{ml}$ flask. The mixture was magnetically stirred at room temperature for $30 \mathrm{~min}$ and then heated to reflux until hydrogen bromide ceased to release. The reaction mixture was cooled to room temperature and then poured into a mixture of $50 \mathrm{ml}$ of $0.1 \mathrm{M} \mathrm{HCl}$ aqueous solution and $100 \mathrm{ml}$ of $\mathrm{CH}_{2} \mathrm{Cl}_{2}$. The layers 
were separated, and the aqueous layer was extracted with $\mathrm{CH}_{2} \mathrm{Cl}_{2}(3 \times 50 \mathrm{ml})$. The combined organic layers were washed successively with saturated NaHCO3 solution, water and brine. The organic layer was transferred to a separatory chamber and added, as a slow stream, to $1 \mathrm{~L}$ methanol to precipitate a solid during $1 \mathrm{~h}$. After the addition was complete, the methanol suspension was stirred vigorously for another $1 \mathrm{~h}$. The methanol suspension was filtered and dried in the vacuum-oven. The crude product was recrystallized from DMF to give HBPBA as a white solid.

1.4 1,3,5,7-tetrakis(1,3-bibromophenyl)adamantane (TBBPA): To the mixture of 1,3,5,7-tetrabromoadamantane $(2.50 \mathrm{~g}, 5.53 \mathrm{mmol})$ and $\mathrm{AlCl}_{3}$ powder $(2.0 \mathrm{~g}, 15.0$ mmol), 1,3-dibromobenzene $(30 \mathrm{ml})$ was added at $0{ }^{\circ} \mathrm{C}$. Then, the mixture was brought to reflux at room temperature for $36 \mathrm{~h}$. After quenching the reaction by adding ice water, the organic layer was diluted with chloroform and filtered. The filtrate was washed with deionized water and brine, dried over $\mathrm{MgSO}_{4}$, and filtered again. After evaporation to remove volatiles, the compound 1,3,5,7-tetrakis(1,3-bibromophenyl)adamantane was obtained as a white solid via crystallization in chloroform.

1.5 Synthesis of MPOF-Ad-2: TEPA (0.10 g, 0.186 mmol), HBPBA (0.15 g, 0.124 mmol), a mixture of NMP (30 ml) and TEA (30 ml), $\mathrm{Pd}\left(\mathrm{PPh}_{3}\right)_{4}(31.3 \mathrm{mg}, 0.019 \mathrm{mmol}$, $10 \mathrm{~mol} \%)$ and CuI (5.9 mg. $0.019 \mathrm{mmol}, 10 \mathrm{~mol} \%)$ were successfully added into a 150 ml Schlenk flask, and degassed by 3 freeze-pump-thaw cycles. The mixture was then heated to $90{ }^{\circ} \mathrm{C}$ and stirred $72 \mathrm{~h}$ under $\mathrm{Ar}$ atmosphere. After cooling to room temperature, the solid precipitate was collected by filtration. The crude product was 
successively subsequently washed with water $(100 \mathrm{ml})$, methanol $(100 \mathrm{ml})$, acetone (100 ml), followed by Soxhlet extraction with THF and chloroform for $24 \mathrm{~h}$, respectively. The insoluble power was dried under vacuum at $90{ }^{\circ} \mathrm{C}$ for $24 \mathrm{~h}$ to give a grey power MPOF-Ad-2 (yield: $93.3 \%$ ).

1.6 Synthesis of MPOF-Ad-3: TEPA (0.10 g, 0.186 mmol), TBBPA (0.15 g, 0.093 mmol), a mixture of NMP (30 ml) and TEA (30 ml), $\mathrm{Pd}\left(\mathrm{PPh}_{3}\right)_{4}(31.3 \mathrm{mg}, 0.019 \mathrm{mmol}$, $10 \mathrm{~mol} \%)$ and $\mathrm{CuI}(5.9 \mathrm{mg} .0 .019 \mathrm{mmol}, 10 \mathrm{~mol} \%)$ were successfully added into a 150 ml Schlenk flask, and degassed by 3 freeze-pump-thaw cycles. The mixture was then heated to $90{ }^{\circ} \mathrm{C}$ and stirred $72 \mathrm{~h}$ under $\mathrm{Ar}$ atmosphere. After cooling to room temperature, the solid precipitate was collected by filtration. The crude product was successively subsequently washed with water $(100 \mathrm{ml})$, methanol $(100 \mathrm{ml})$, acetone (100 ml), followed by Soxhlet extraction with THF and chloroform for $24 \mathrm{~h}$, respectively. The insoluble power was dried under vacuum at $90{ }^{\circ} \mathrm{C}$ for $24 \mathrm{~h}$ to give a grey power MPOF-Ad-3 (yield: $83.7 \%$ ).

Scheme S1. Synthetic routes of the TIPA, TEPA, HBPBA and TBBPA

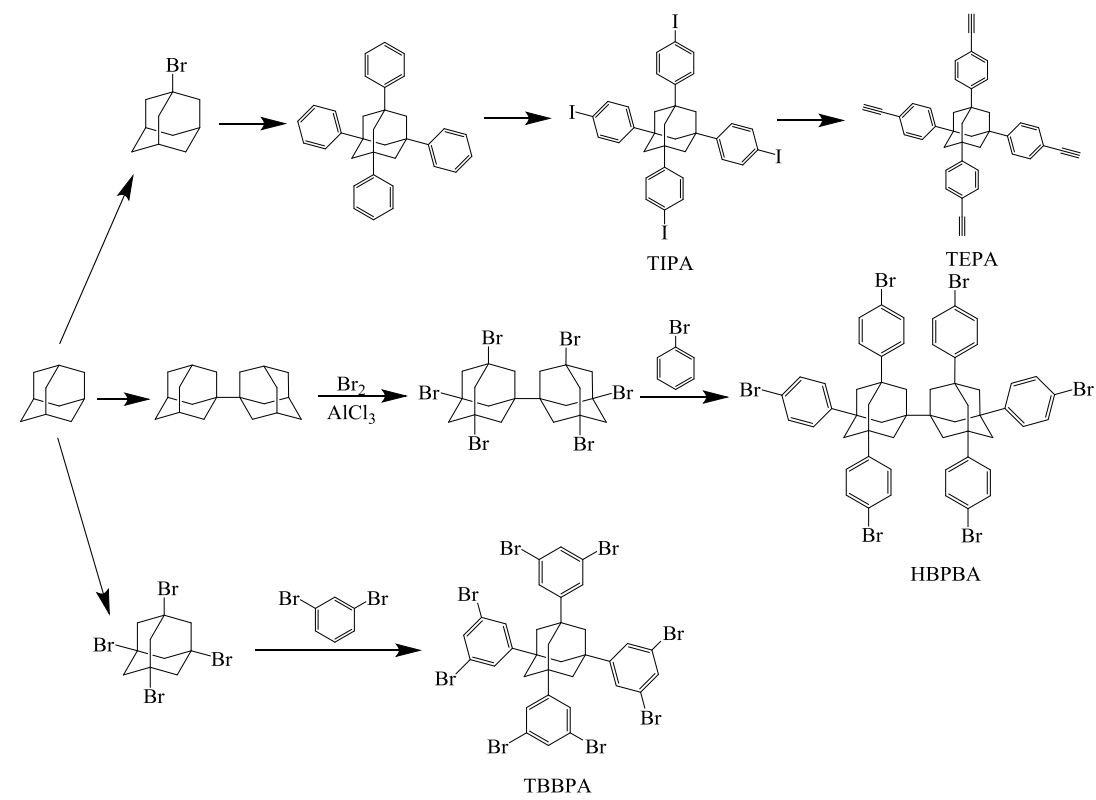


Solid-state ${ }^{13} \mathrm{C}$ NMR spectra assignment of MPOF-Ads networks

Table S1. The ${ }^{13} \mathrm{C}$ CP/MAS NMR spectra assignment of the MPOF-Ad-1, MPOF-Ad-2 and MPOF-Ad-3 networks (chemical shifts in ppm).

$\begin{array}{lllllllllllllll}\mathrm{C}_{1}-\mathrm{C}_{2} & \mathrm{C}_{3} & \mathrm{C}_{4} & \mathrm{C}_{5} & \mathrm{C}_{6} & \mathrm{C}_{7} & \mathrm{C}_{8} & \mathrm{C}_{9} & \mathrm{C}_{10} & \mathrm{C}_{11} & \mathrm{C}_{12} & \mathrm{C}_{13} & \mathrm{C}_{14} & \mathrm{C}_{15} & \mathrm{C}_{16}\end{array}$

\begin{tabular}{|c|c|c|c|c|c|c|c|c|c|c|c|c|c|c|}
\hline \multicolumn{15}{|l|}{ MPOF } \\
\hline & $35-50$ & 149.7 & 127.8 & 131.3 & 124.6 & 96.8 & - & - & - & - & - & - & - & - \\
\hline \multicolumn{15}{|l|}{-Ad-1 } \\
\hline \multicolumn{15}{|l|}{ MPOF } \\
\hline & $35-50$ & 149.6 & 127.8 & 131.0 & 124.7 & 96.6 & 96.6 & 124.7 & 131.0 & 127.8 & 149.6 & $35-50$ & & \\
\hline \multicolumn{15}{|l|}{-Ad-2 } \\
\hline \multicolumn{15}{|l|}{ MPOF } \\
\hline & $35-50$ & 150.7 & 128.0 & 131.4 & 125.2 & 97.7 & 97.7 & 125.2 & 131.4 & 150.7 & $35-50$ & 131.4 & - & - \\
\hline -Ad-3 & & & & & & & & & & & & & & \\
\hline
\end{tabular}

XRD pattern for the MPOF-Ads networks

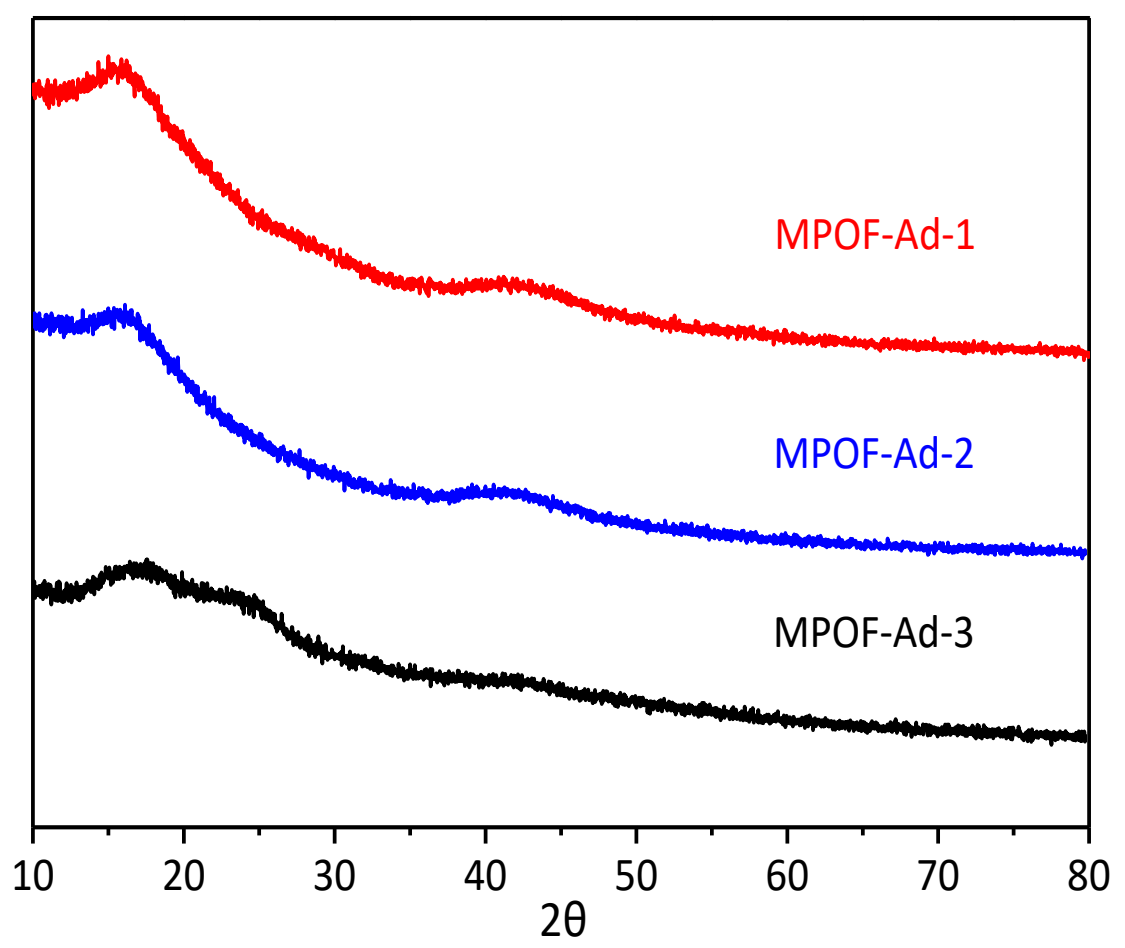

Figure S1. XRD pattern for the three MPOF-Ads networks 
FTIR spectra of the as-synthesized MPOF-Ads networks compared to that had been heated and immersed in strong acid and base, respectively.

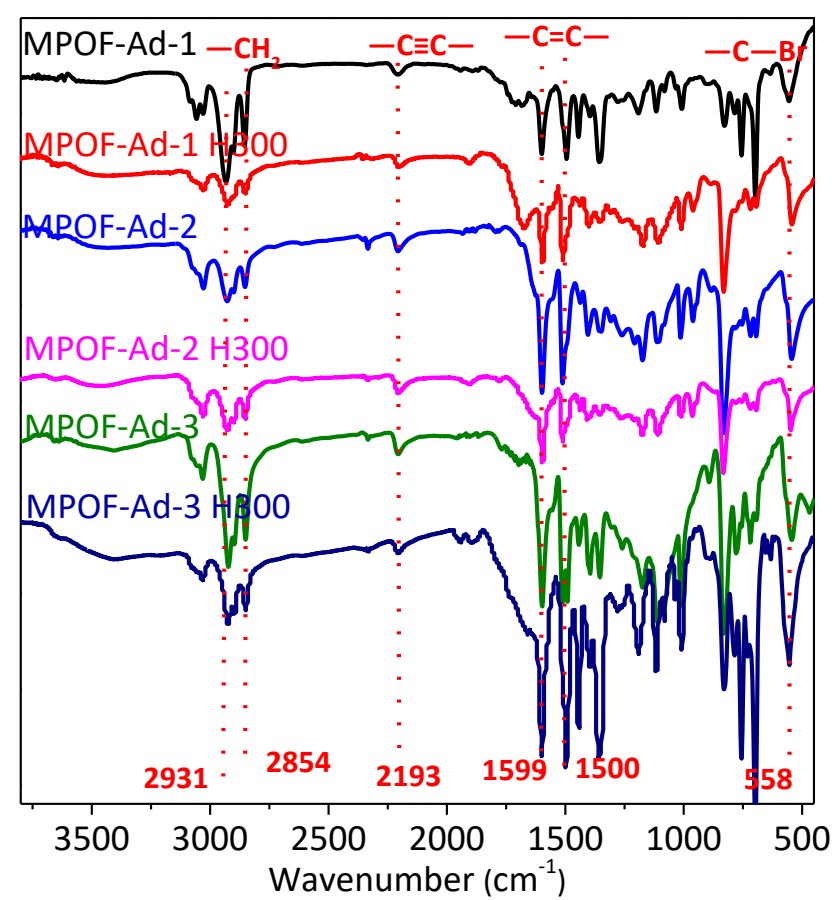

Figure S2. FTIR spectra of MPOF-Ads networks compared to that had been heated isothermally at $300^{\circ} \mathrm{C}$ in air for $8 \mathrm{~h}$.

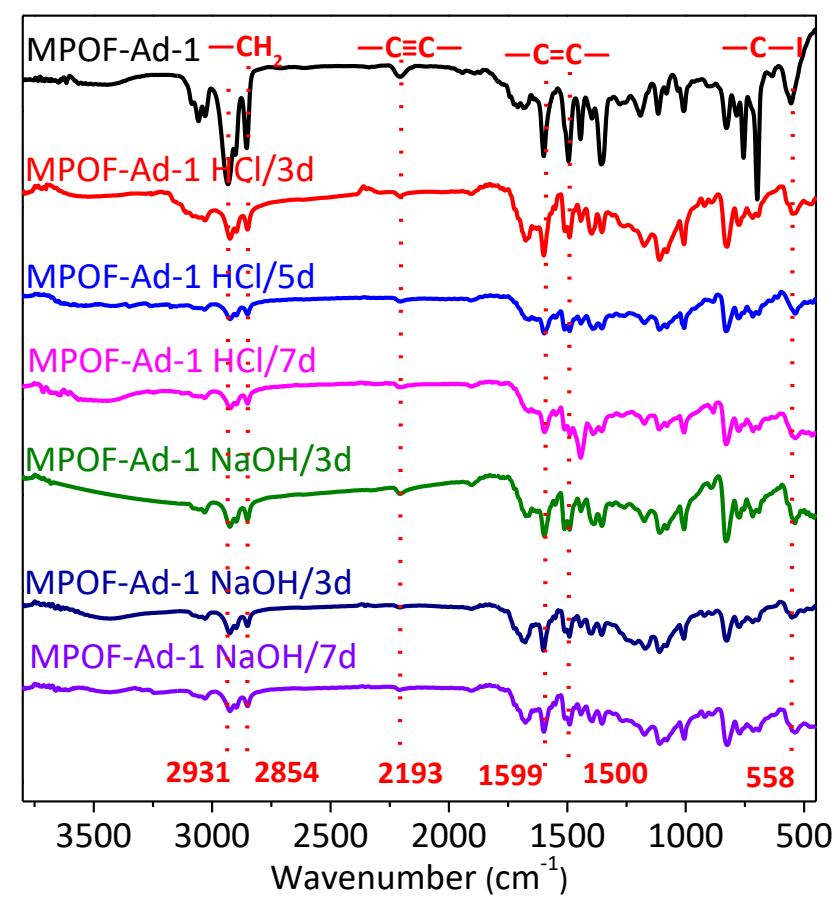

Figure S3. FTIR spectra of MPOF-Ad-1 (black) compared to that had been immersed in $12 \mathrm{M}$ concentrated $\mathrm{HCl}$ and $25 \mathrm{M} \mathrm{NaOH}$ aqueous for 3, 5 and 7 days, respectively 


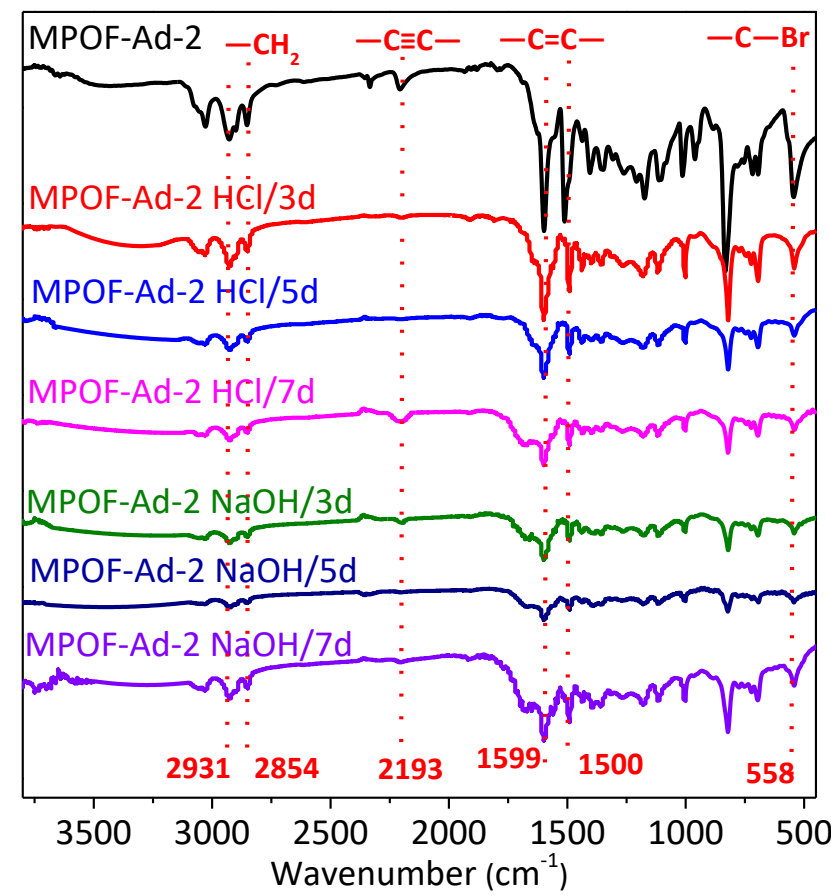

Figure S4. FTIR spectra of MPOF-Ad-2 (red) compared to that had been immersed in $12 \mathrm{M}$ concentrated $\mathrm{HCl}$ and $25 \mathrm{M} \mathrm{NaOH}$ aqueous for 3,5 and 7 days, respectively

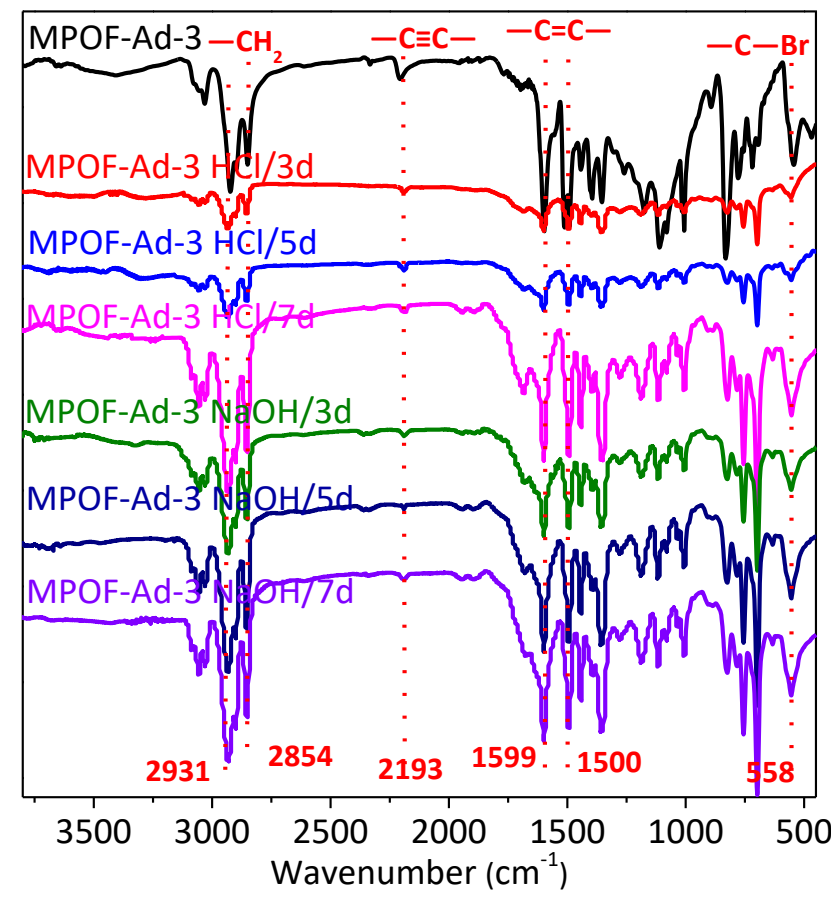

Figure S5. FTIR spectra of MPOF-Ad-3 (red) compared to that had been immersed in $12 \mathrm{M}$ concentrated $\mathrm{HCl}$ and $25 \mathrm{M} \mathrm{NaOH}$ aqueous for 3, 5 and 7 days, respectively 
$\mathrm{CH}_{4}$ Adsorption isotherms for the MPOF-Ads networks

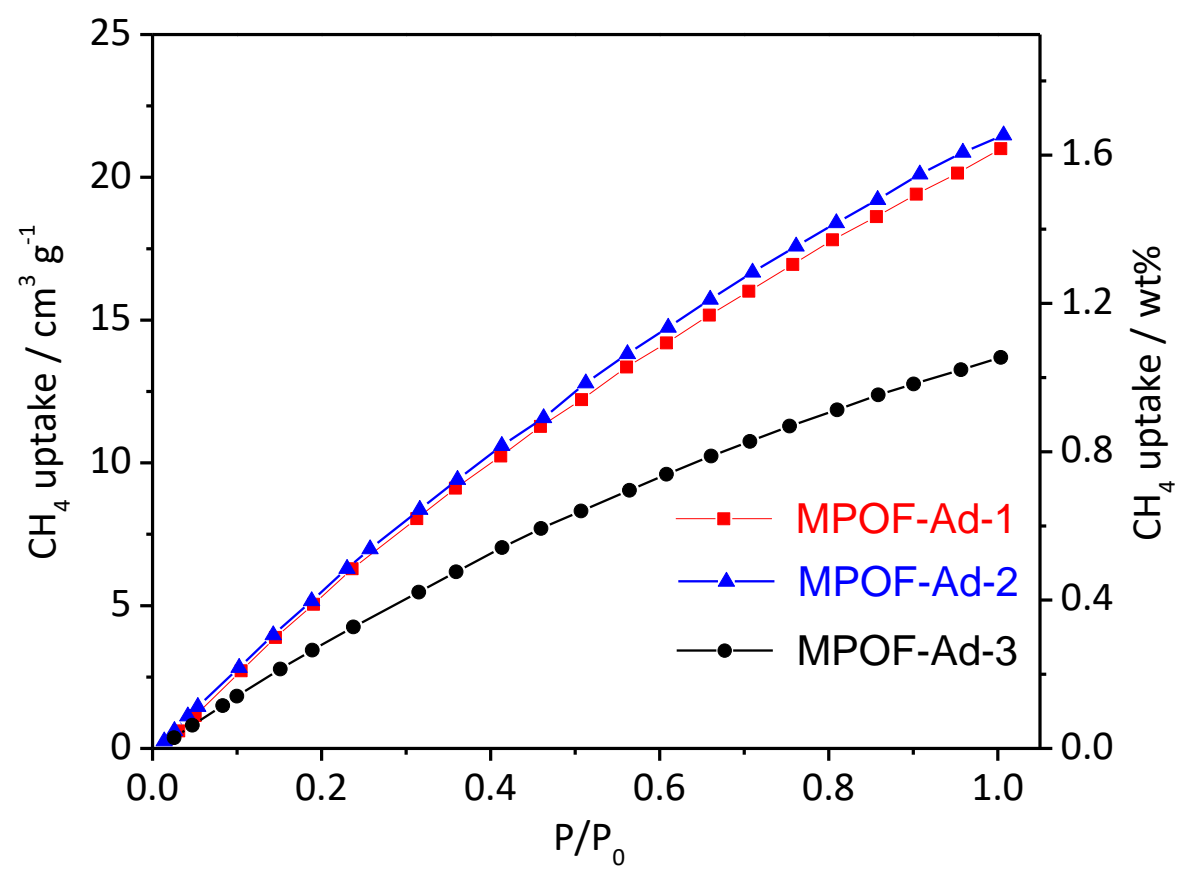

Figure S6. Adsorption isotherms of $\mathrm{CH}_{4}$ at $273 \mathrm{~K}$

$\mathrm{N}_{2}$ Adsorption isotherms for the MPOF-Ads networks

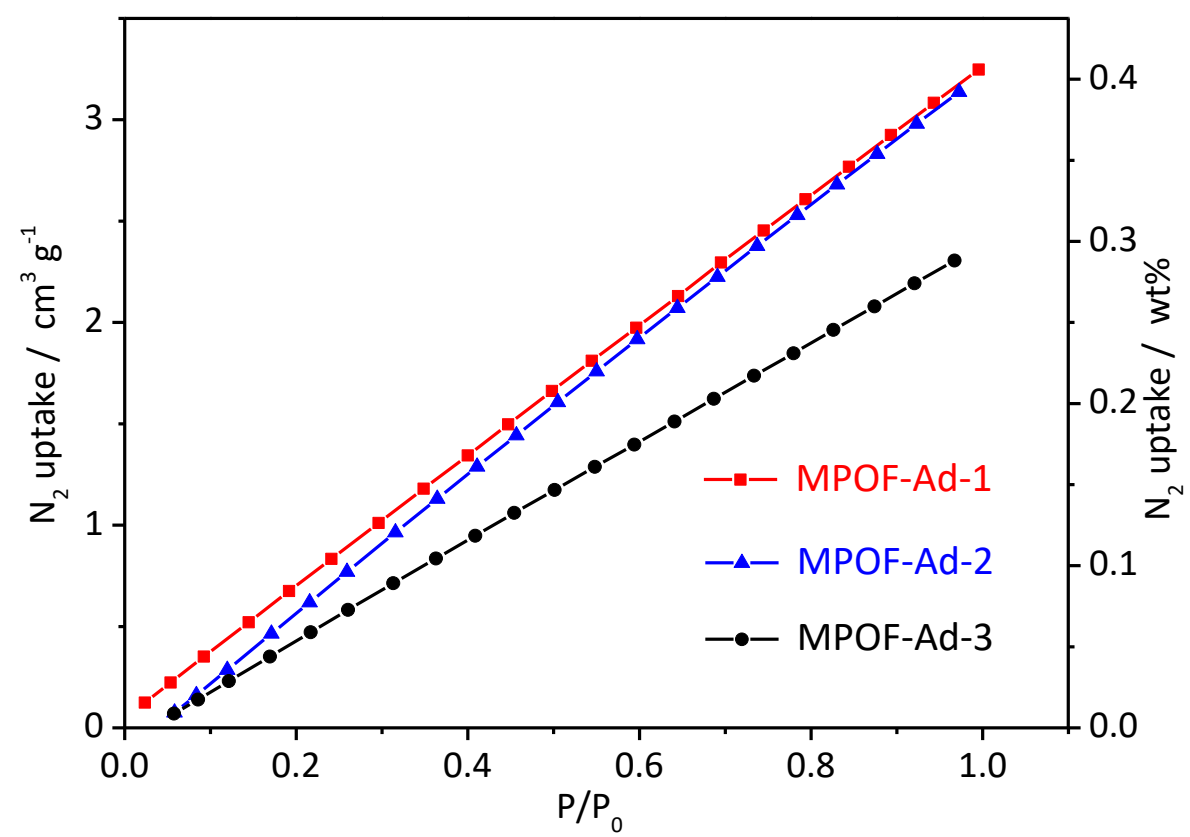

Figure S7. Adsorption isotherms of $\mathrm{N}_{2}$ at $77 \mathrm{~K}$

Calculations forisosteric heat of adsorption $\left(Q_{s t}\right)$ of MPOF-Ads networks

The $\mathrm{Q}_{\mathrm{st}}$ of $\mathrm{CO}_{2}$ for the three MPOF-Ads networks were calculated from the 
adsorption isotherms measured at different temperatures in term of Clausius-Clapeyron equation:

$$
\ln p=\frac{Q_{s t}}{R T}+C
$$

where $R, C, p$ and $T$ are the gas costant, equation constant, the pressure and temperature at the equilibrium state, respectively.

\section{Initial slope selectivity studies for MPOF-Ads networks}

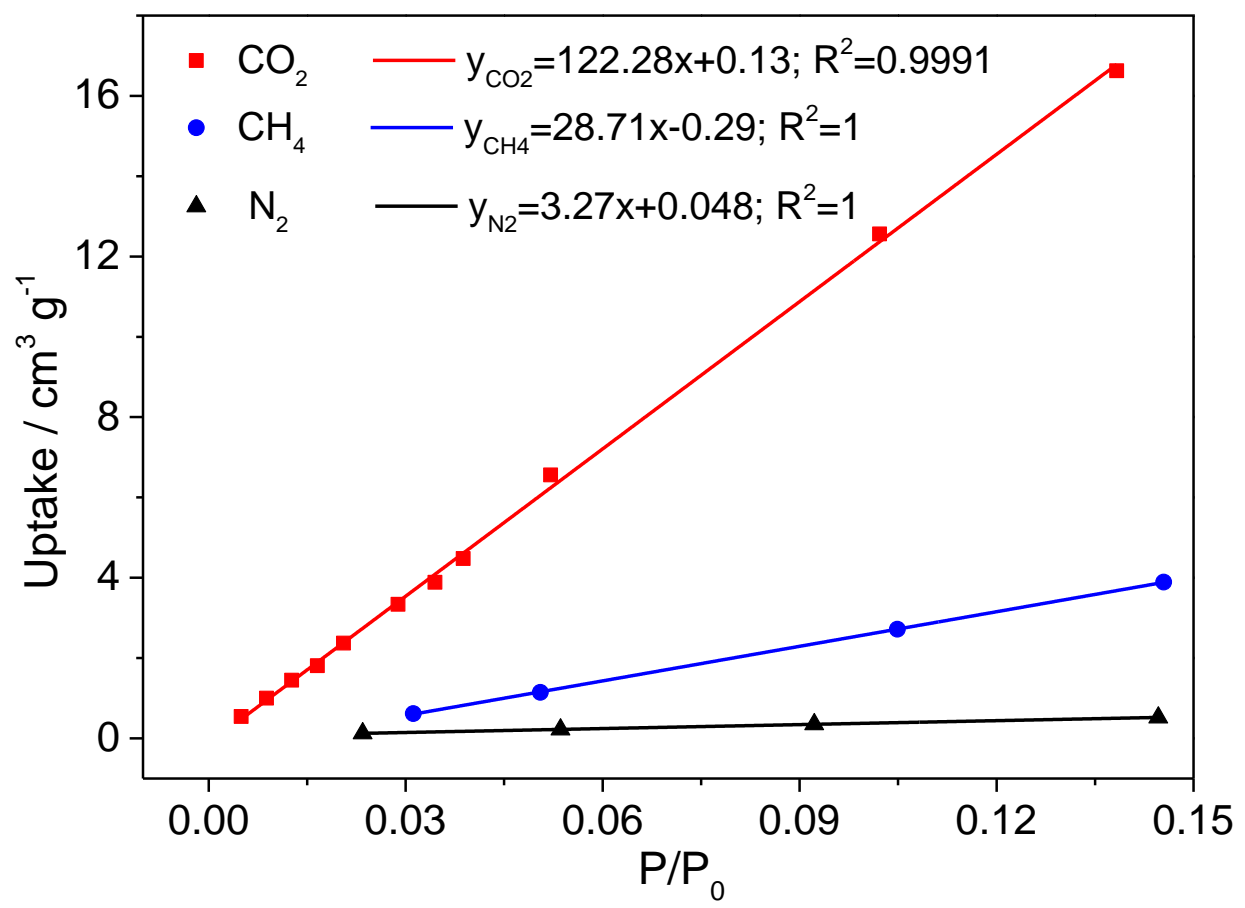

Figure S8. The fitted straight line and initial slopes in the Henry region $\left(\mathrm{P} / \mathrm{P}_{0}<0.15\right)$ of the adsorption isotherms for MPOF-Ad-1 


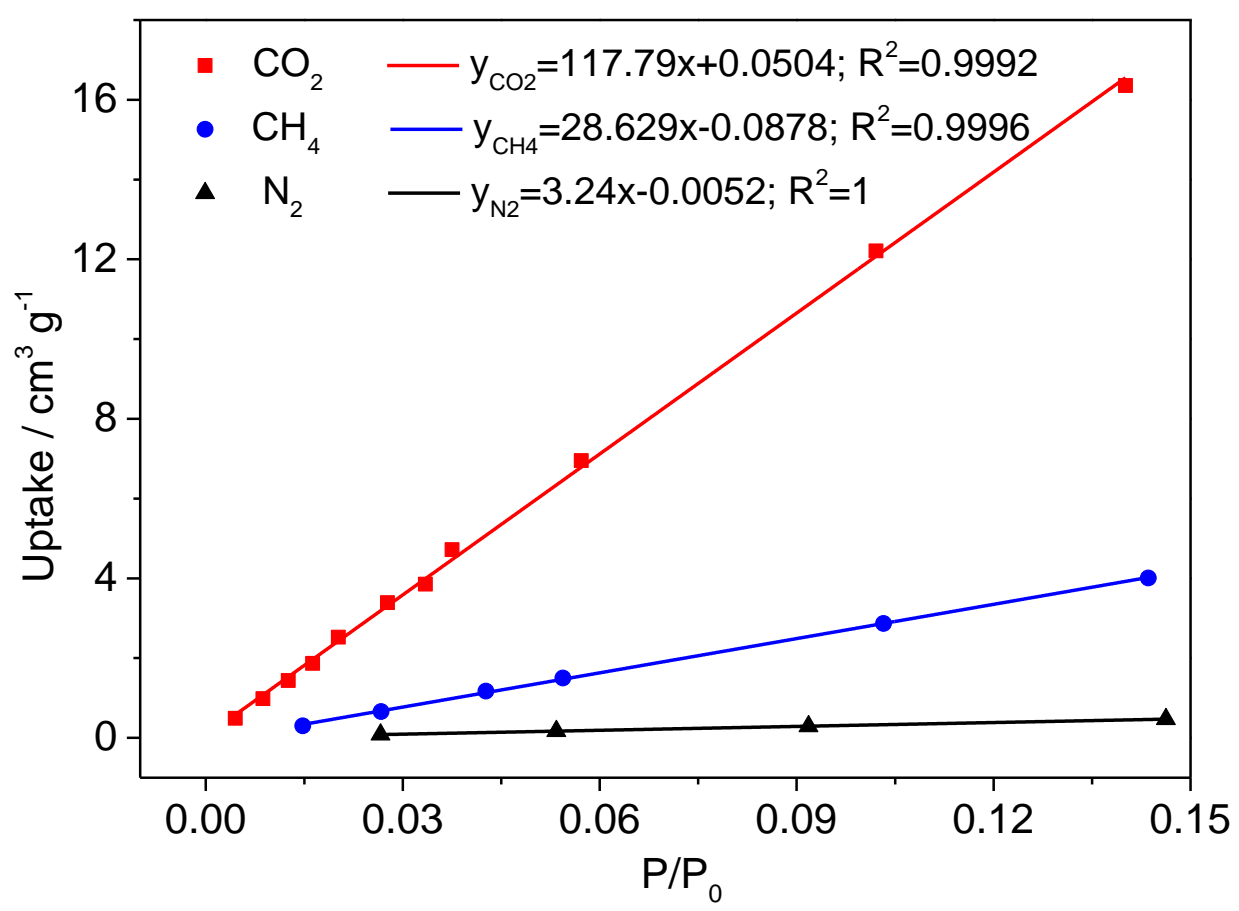

Figure S9. The fitted straight line and initial slopes in the Henry region $\left(\mathrm{P} / \mathrm{P}_{0}<0.15\right)$ of the adsorption isotherms for MPOF-Ad-2

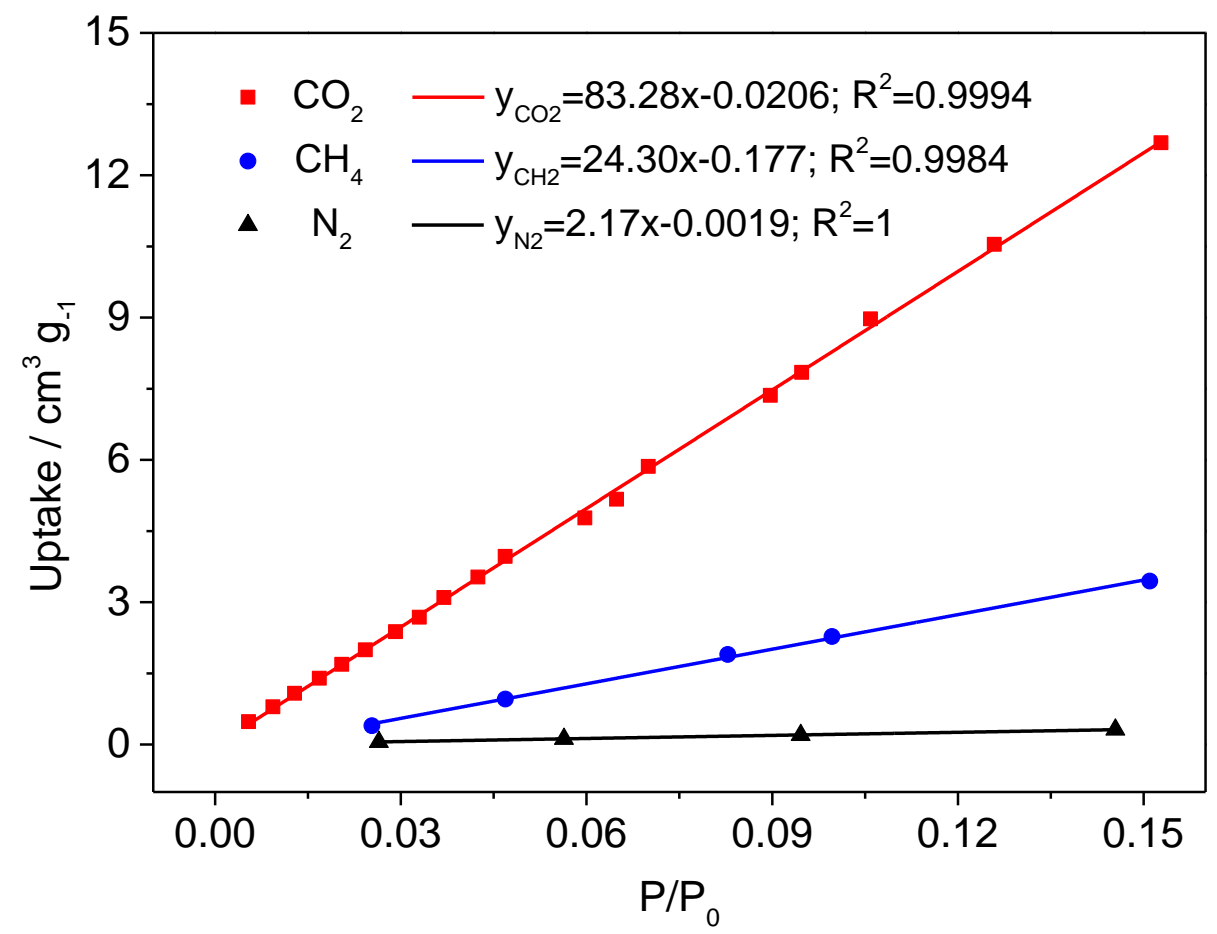

Figure S10. The fitted straight line and initial slopes in the Henry region $\left(\mathrm{P} / \mathrm{P}_{0}<0.15\right)$ of the adsorption isotherms for MPOF-Ad-3

Calculations for selectivites of $\mathrm{CO}_{2} / \mathrm{CH}_{4}$ and $\mathrm{CO}_{2} / \mathrm{N}_{2}$ gas mixtures by Ideal Adsorption Solution Theory (IAST) method 
To study the potential of MPOF-Ads networks for gas separation, IAST was performed to evaluate the adsorption selectivities of $\mathrm{CO}_{2} / \mathrm{CH}_{4}$ and $\mathrm{CO}_{2} / \mathrm{N}_{2}$ gas mixtures based on the experimental gas adsorption isotherms. According to Myers and Prausnitz,the method of IAST can be reduced to the mathematical integration:

$$
\int_{t=0}^{\frac{P y_{1}}{x_{1}}} F_{1}(t) d \ln t=\int_{t=0}^{\frac{P y_{2}}{x_{2}}} F_{2}(t) d \ln t
$$

Equation S2

where $p$ is the total pressure, $x_{i}$ is the adsorbed phase molar ratio of gas $i, y_{i}$ is the bulk phase molar ratio of gas $i$ and the function $F_{i}(t)$ is a fitting function for the pure component $\mathrm{i}$ based on the Dual-site Langmuir Freundlish (DSLF) model (for $\mathrm{CO}_{2}$ adsorption isotherms) and single-site Langmuir-Freundlich (SSLF) model (for $\mathrm{CH}_{4}$ and $\mathrm{N}_{2}$ adsorption isotherms).

Dual-site Langmir-Freundlich (DSLF) model:

$$
N=N_{1}^{\max } \times \frac{b_{1} p^{\frac{1}{c_{1}}}}{1+b_{1} p^{\frac{1}{c_{1}}}}+N_{2}^{\max } \times \frac{b_{2} p^{\frac{1}{c_{2}}}}{1+b_{2} p^{\frac{1}{c_{2}}}}
$$

In the model, $p$ is the pressure of the bulk gas at equilubrium with the adsorbed phase, $N_{1}^{\max }$ and $N_{2}^{\max }$ are the saturation capacities of sites 1 and $2 . b_{1}$ and $b_{2}$ are the affinity coefficients of sites 1 and 2. $c_{1}$ and $c_{2}$ are the deviations from an ideal homogeneous surface.

Single-site Langmir-Freundlich (SSLF) model: 


$$
N=N^{\max } \times \frac{b p^{\frac{1}{c}}}{1+b p^{\frac{1}{c}}}
$$

In the model, $p, N^{\max }, b$ and c represent the pressure of the bulk gas at equilubrium with the adsorbed phase, saturation capacities, affinity coefficients and the deviations from an ideal homogeneous surface, respectively.

Since $x_{1}+x_{2}=1$ and $y_{1}+y_{2}=1$, the adsorption selectivity $\left(\mathrm{S}_{\mathrm{A} / \mathrm{B}}\right)$ of gas A over gas $\mathrm{B}$ is defined as:

$$
S_{A / B}=\frac{x_{A} / y_{A}}{x_{B} / y_{B}}
$$

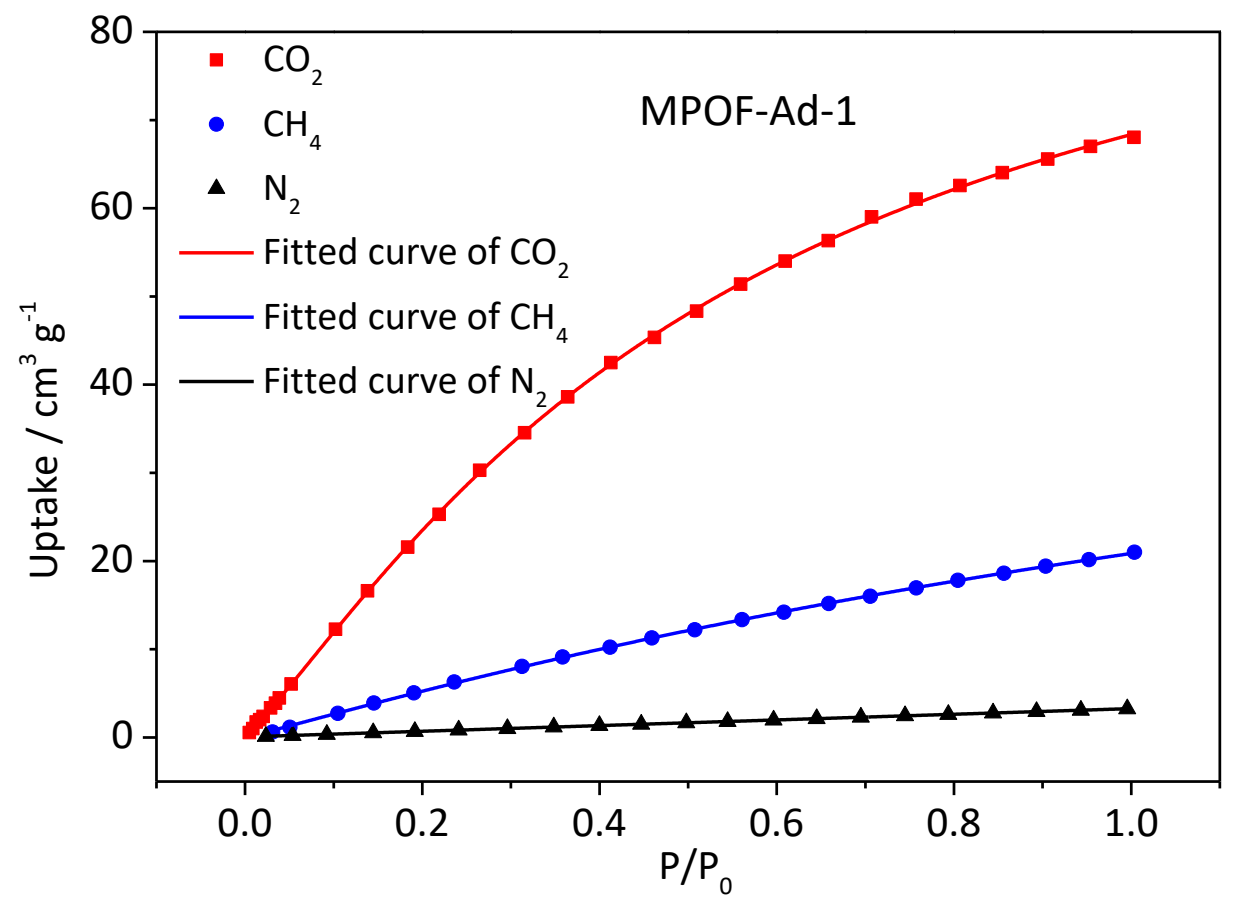

Figure S11. The fitted curves of gas uptake for MPOF-Ad-1: (red) dual-site Langmuir-Freundlich (DSLF) model fitting of the $\mathrm{CO}_{2}$ adsorption isotherms at $273 \mathrm{~K}$, (bule) single-site Langmuir-Freundlich (SSLF) model fitting of the $\mathrm{CH}_{4}$ adsorption isotherms, (black) SSLF model fitting of the $\mathrm{N}_{2}$ adsorption isotherms 


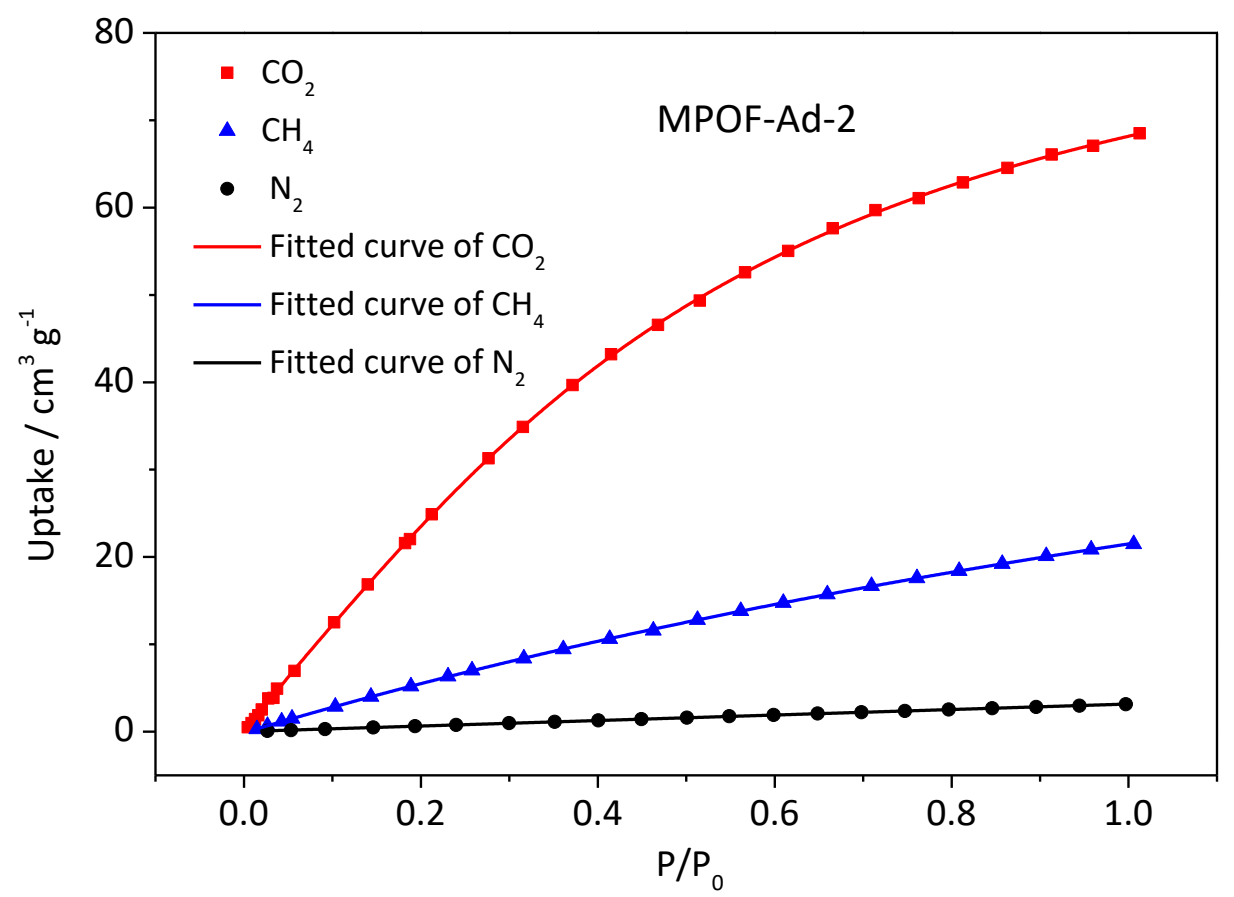

Figure S12. The fitted curves of gas uptake for MPOF-Ad-2: (red) dual-site Langmuir-Freundlich (DSLF) model fitting of the $\mathrm{CO}_{2}$ adsorption isotherms at $273 \mathrm{~K}$, (bule) single-site Langmuir-Freundlich (SSLF) model fitting of the $\mathrm{CH}_{4}$ adsorption isotherms, (black) SSLF model fitting of the $\mathrm{N}_{2}$ adsorption isotherms

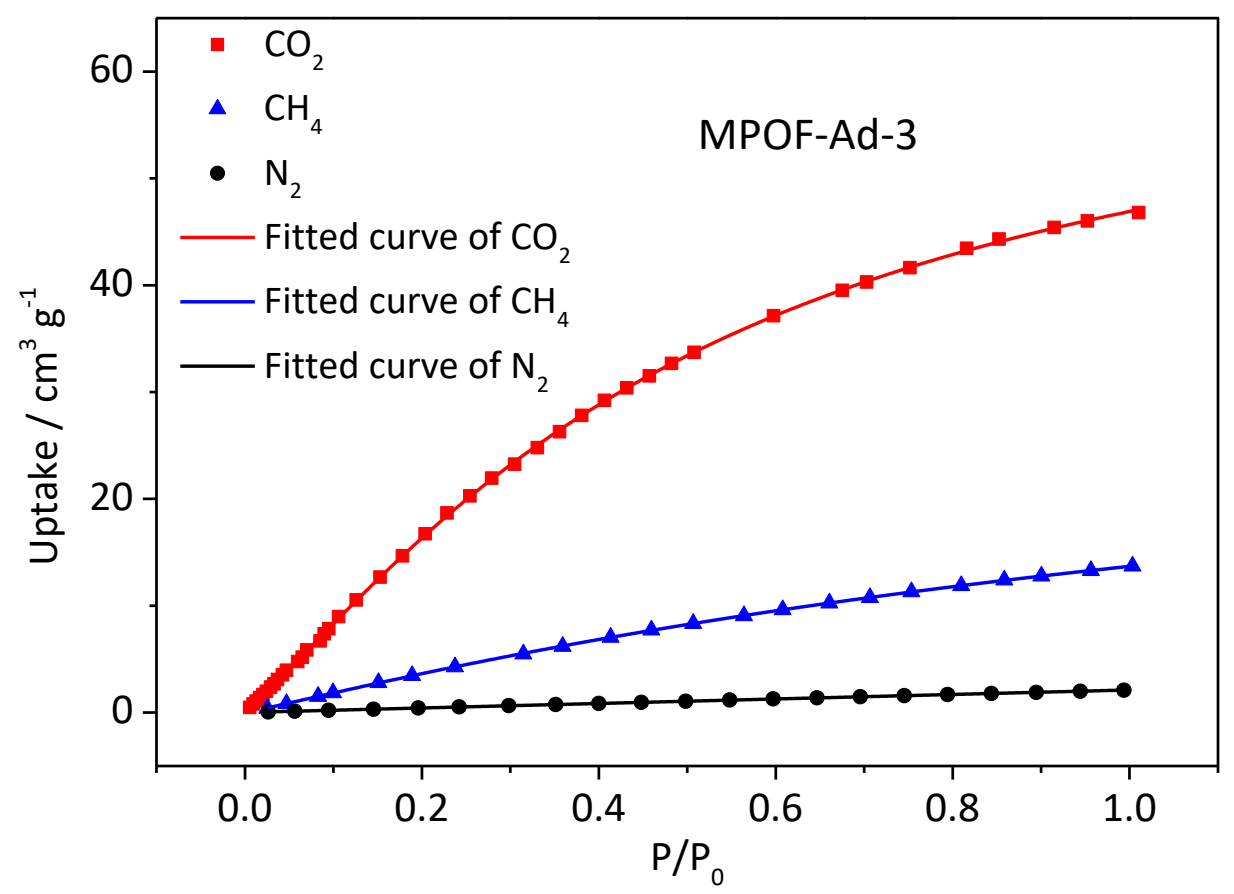

Figure S13. The fitted curves of gas uptake for MPOF-Ad-3: (red) dual-site Langmuir-Freundlich (DSLF) model fitting of the $\mathrm{CO}_{2}$ adsorption isotherms at $273 \mathrm{~K}$, (bule) single-site Langmuir-Freundlich (SSLF) model fitting of the $\mathrm{CH}_{4}$ adsorption isotherms, (black) SSLF model fitting of the $\mathrm{N}_{2}$ adsorption isotherms 
Table S2. Equation parmetrs prameters for the DSLF isotherm model of $\mathrm{CO}_{2}$ adsorption isotherms

\begin{tabular}{cccccccc}
\hline Samples & $N_{l}{ }^{\max }$ & $b_{1}$ & $C_{1}$ & $N_{2}{ }^{\max }$ & $b_{2}$ & $c_{2}$ & $R^{2}$ \\
\hline MPOF-Ad-1 & 88.0898 & 2.2364 & 0.7670 & 9.9821 & 2.8619 & 1.2614 & 0.99992 \\
MPOF-Ad-2 & 58.1999 & 2.2867 & 0.9818 & 34.9749 & 3.7822 & 0.5393 & 0.99995 \\
& & & & & & & \\
MPOF-Ad-3 & 62.4966 & 2.4328 & 0.7693 & 3.1740 & 4.6291 & 1.4179 & 0.99990 \\
\hline
\end{tabular}

Table S3. Equation parmetrs prameters for the DSLF isotherm model of $\mathrm{CH}_{4}$ adsorption isotherms

\begin{tabular}{ccccc} 
Samples & $N^{\max }$ & $b$ & $c$ & $R^{2}$ \\
\hline MPOF-Ad-1 & 63.8435 & 0.4853 & 0.9518 & 0.99984 \\
MPOF-Ad-2 & 66.3380 & 0.4786 & 0.9624 & 0.99994 \\
MPOF-Ad-3 & 34.2157 & 0.6669 & 0.9335 & 0.99997 \\
\hline
\end{tabular}

Table S4. Equation parmetrs prameters for the DSLF isotherm model of $\mathrm{N}_{2}$ adsorption isotherms

\begin{tabular}{ccccc}
\hline Samples & $N^{\max }$ & $b$ & $c$ & $R^{2}$ \\
\hline MPOF-Ad-1 & 201.2583 & 0.0164 & 1.0347 & 0.99979 \\
MPOF-Ad-2 & 43.7292 & 0.0773 & 0.9787 & 1.00000 \\
MPOF-Ad-3 & 98.9302 & 0.0218 & 1.0028 & 0.99999 \\
\hline
\end{tabular}


Comparison of the gas uptake capablities of MPOF-Ads networks with literature reported microporous organic frameworks

Table S5. Comparison of the gas uptake capablities of MPOF-Ads networks with literature reported microporous organic frameworks

\begin{tabular}{|c|c|c|c|c|c|c|c|c|}
\hline \multirow{2}{*}{ Networks } & \multirow{2}{*}{$\begin{array}{l}\text { BET surface } \\
\text { area }\left(\mathrm{m}^{2} \mathrm{~g}^{-1}\right)\end{array}$} & \multicolumn{2}{|c|}{$\mathrm{CO}_{2}$ uptake $\left(\mathrm{cm}^{3} \mathrm{~g}^{-1}\right)$} & \multirow{2}{*}{$\begin{array}{l}\mathrm{Q}_{\mathrm{st}}(\mathrm{kJ} \\
\left.\mathrm{mol}^{-1}\right)\end{array}$} & \multirow{2}{*}{$\begin{array}{c}\mathrm{CH}_{4} \text { uptake } \\
\left(\mathrm{cm}^{3} \mathrm{~g}^{-1}\right)\end{array}$} & \multicolumn{2}{|c|}{ Selectivity } & \multirow{2}{*}{ Ref. } \\
\hline & & $273 \mathrm{~K} / 1.0 \mathrm{bar}$ & $298 \mathrm{~K} / 1.0 \mathrm{bar}$ & & & $\mathrm{CO}_{2} / \mathrm{CH}_{4}$ & $\mathrm{CO}_{2} / \mathrm{N}_{2}$ & \\
\hline MPOF-Ad-1 & 734.1 & 69.5 & 44.3 & 30.3 & 21.0 & 4.3 & 37.4 & \\
\hline MPOF-Ad-2 & 737.3 & 68.5 & 42.4 & 27.3 & 21.5 & 4.1 & 36.3 & This \\
\hline MPOF-Ad-3 & 437.5 & 46.0 & 32.4 & 19.5 & 13.7 & 4.4 & 38.4 & work \\
\hline HBPBA-D & 488 & 45.5 & - & - & 24.9 & 4.1 & - & \\
\hline TBBPA-D & 395 & 45.1 & - & - & 21.8 & 4.6 & - & \\
\hline $\mathrm{T} 1$ & 591 & 49.1 & - & - & 23.5 & 3.58 & 42.6 & \\
\hline $\mathrm{T} 2$ & 640 & 49.6 & - & - & 18.9 & 4.05 & 14.7 & \\
\hline $\mathrm{H} 1$ & 407 & 41.5 & - & - & 23.8 & 3.54 & 38.7 & \\
\hline $\mathrm{H} 2$ & 755 & 55.6 & - & - & 27.6 & 3.6 & 12.6 & \\
\hline CMOP-1 & 431 & 41.2 & - & - & - & - & - & \\
\hline CMOP-2 & 406 & 36.5 & - & - & - & - & - & \\
\hline DA-CMP1 & 662 & 50.7 & 30.0 & 30.2 & 14.9 & 5.4 & 37.1 & \\
\hline DA-CMP2 & 603 & 36.5 & 21.1 & 30.8 & 10.9 & 5.4 & 33.1 & \\
\hline Azo-CMP1 & 1146 & 80.7 & 47.8 & 31.5 & 24.2 & 5.8 & 42.1 & \\
\hline Azo-CMP1 & 898 & 70.5 & 43.6 & 31.2 & 19.9 & 5.3 & 44.4 & \\
\hline BDPCMP-1 & 482 & 37.4 & 22.9 & 25.0 & 11.7 & 5.4 & 38.6 & \\
\hline BDPCMP-2 & 582 & 50.1 & 32.3 & 24.8 & 15.6 & 5.1 & 32.3 & \\
\hline
\end{tabular}




\begin{tabular}{|c|c|c|c|c|c|c|c|c|}
\hline BDPCMP-3 & 725 & 45.2 & 27.6 & 23.0 & 13.4 & 5.1 & 31.1 & \\
\hline BDPCMP-4 & 501 & 42.5 & 27.4 & 27.3 & 12.5 & 5.4 & 34.1 & \\
\hline NOP-54 & 1178 & 71.8 & - & - & 20.2 & 13.9 & 56.1 & S6 \\
\hline HCM-1 & 855 & 115.7 & 31.6 & - & - & - & 72 & \\
\hline $\mathrm{HCM}-2$ & 425 & 151.3 & 26.3 & - & - & - & 70 & S7 \\
\hline HCM-3 & 566 & 158.0 & 33.4 & - & - & - & 23 & \\
\hline $\mathrm{P}-\mathrm{PCz}$ & 656 & 124.0 & 66.1 & 30.9 & - & - & 32 & S8 \\
\hline \multicolumn{9}{|l|}{$\mathrm{PDA}_{0.3} / \mathrm{MA}_{0.7^{-}}$} \\
\hline & 866 & 102.4 & 81.0 & 37.5 & - & - & - & S9 \\
\hline \multicolumn{9}{|l|}{2} \\
\hline TrzPOP-1 & 998 & 137.8 & 78.6 & 29 & - & - & 67 & \\
\hline TrzPOP-2 & 868 & 167.1 & 100.6 & 34 & - & - & 117 & $\mathrm{~S} 10$ \\
\hline TrzPOP-2 & 772 & 190.1 & 113.3 & 37 & - & - & 96 & \\
\hline
\end{tabular}

${ }^{\mathrm{a}}$ our previous work

Computational details and corresponding results

Computational details

Three structural molecular units for the corresponding MPOF-Ads networks (MPOF-Ad-1, MPOF-Ad-2 and MPOF-Ad-3) were modeled at density functional theory (DFT) using Becke's three parameter hybrid functional with the Lee-Yang-Parr correlation functional (B3LYP). The natural atomic charges have been evaluated by applying the natural population analysis (NPA) to the fully optimized geometries. The geometries of our three structural molecular units and $\mathrm{CO}_{2}$ adsorbed on networks have been determined via full geometry optimization with no symmetry constraints using 
B3LYP calculations. The binding energy $\left(E_{b}\right)$ between the MPOF-Ads networks and the adsorbed $\mathrm{CO}_{2}$ is defined as:

$$
E_{b}=E\left(M P O F-A d s / C O_{2}\right)-E(M P O F-A d s)-E\left(C_{2}\right) \quad \text { Equation S6 }
$$

Where $E_{b}$ (MPOF-Ads/CO $\mathrm{CO}_{2}$ ) denotes the energy of the MPOF-Ads and $\mathrm{CO}_{2}$ complexes, while $E_{b}$ (MPOF-Ads) and $E_{b}\left(\mathrm{CO}_{2}\right)$ denote the energies of MPOF-Ads and $\mathrm{CO}_{2}$, respectively. Typically, the energies mentioned above were calculated through Single-point second-order MØller-Plesset perturbation theory (MP2) energy calculations on the DFT optimized geometries. 6-31 + G* basis set was used for all atoms of MPOF-Ads models and $\mathrm{CO}_{2}$ molecule. All DFT and MP2 calculations have been carried out using the Gaussian 09W program package (Ref. S11).

\section{Computational results}

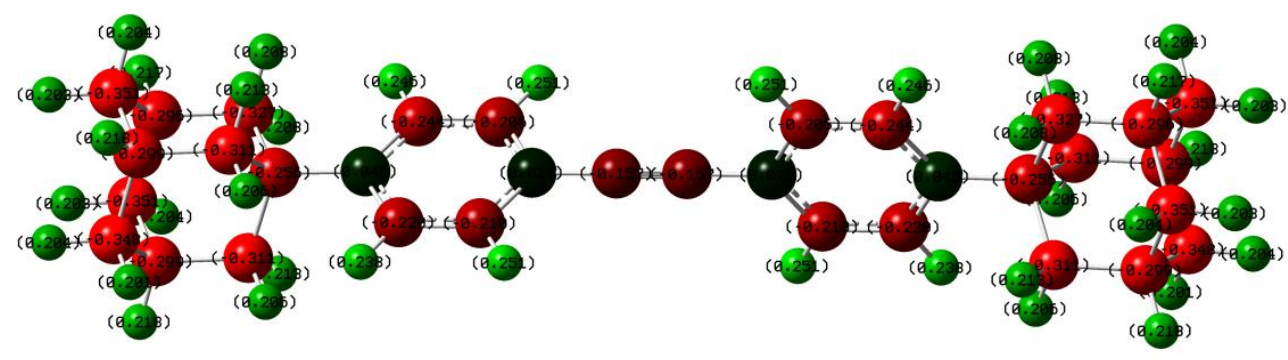

Natural atomic charges

$-0.352$

(a) MPOF-Ad-1

\subsection{2}

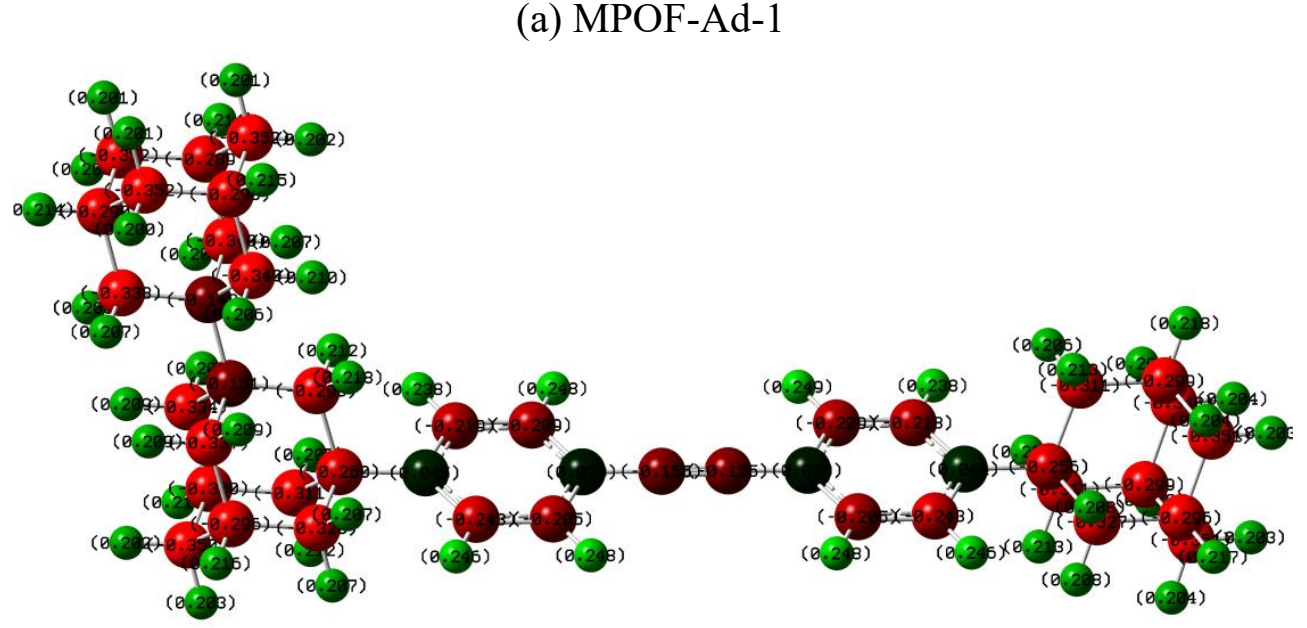




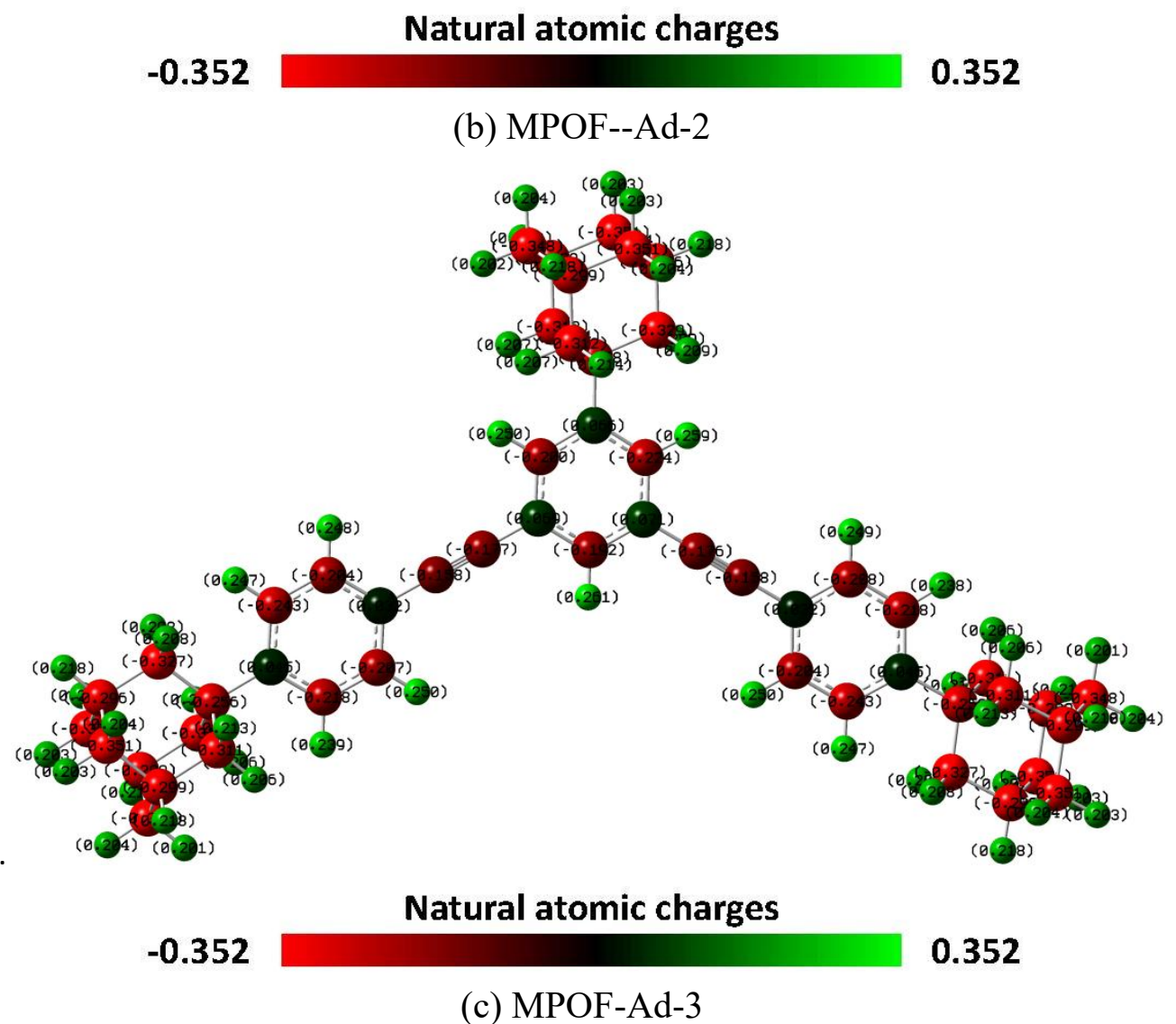

Figure S14. Natural atomic charges on (a) MPOF-Ad-1, (b) MPOF-Ad-2 and (c) MPOF-Ad-3

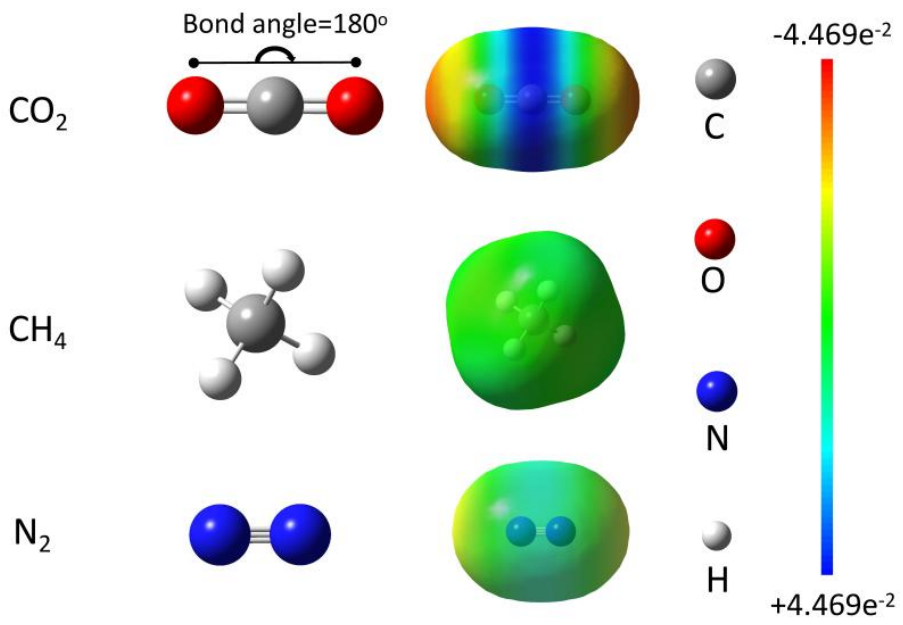

Figure S15. The fully optimized geometries (left) and electron density mapped surfaces (right) of $\mathrm{CO}_{2}, \mathrm{CH}_{4}$ and $\mathrm{N}_{2}$ 
(a)

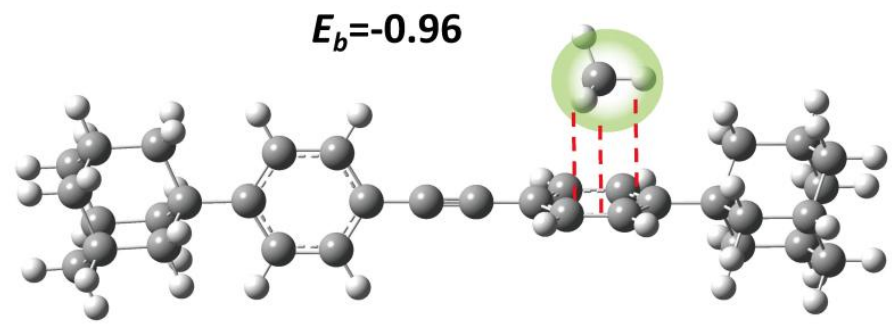

(b)

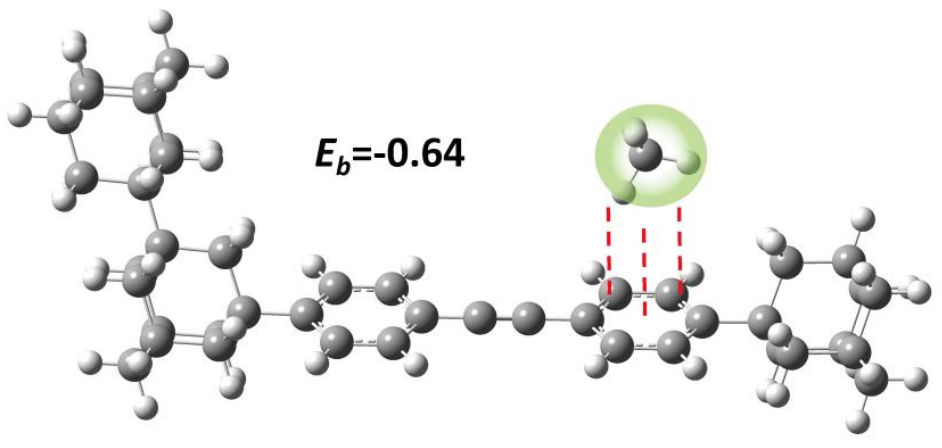

(c)

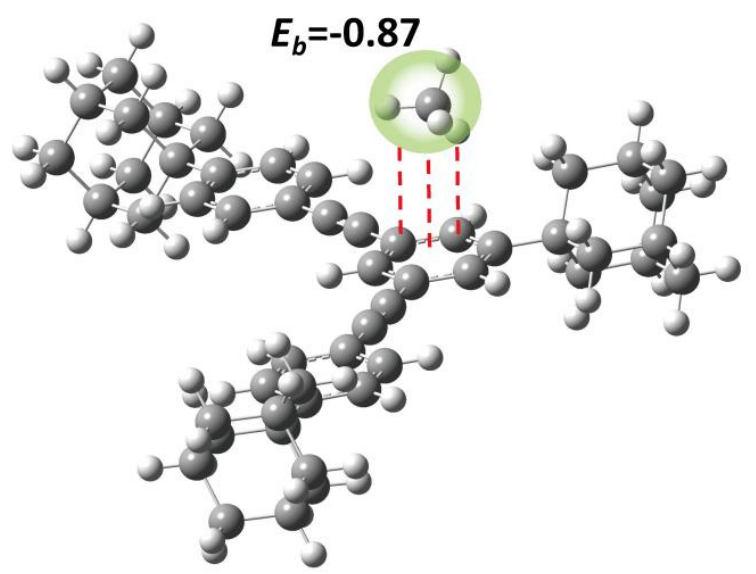

Figure S16. Calculated binding sites and binding energies $\left(E_{b}\right.$ in $\left.\mathrm{kcal} \mathrm{mol}^{-1}\right)$ of $\mathrm{CH}_{4}$ located above the phenyl rings of the fully optimized MPOF-Ad-1 (a), MPOF-Ad-2 (b) and MPOF-Ad-3 (c). 
(a)

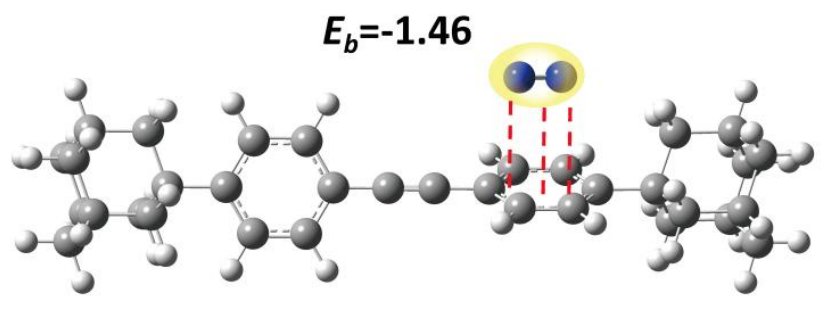

(b)

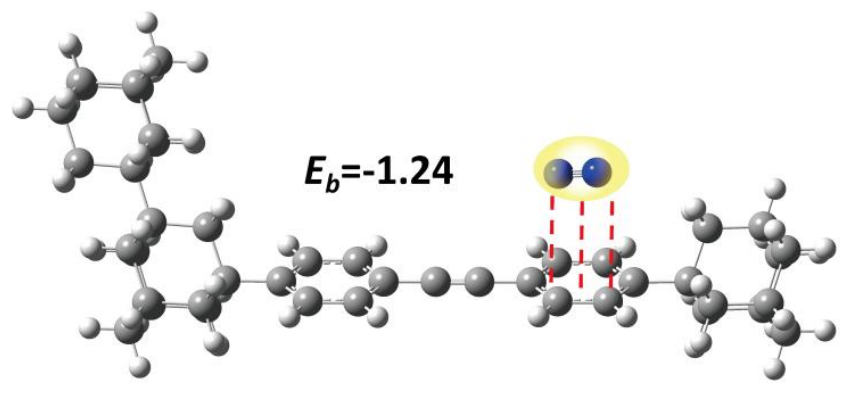

(c)

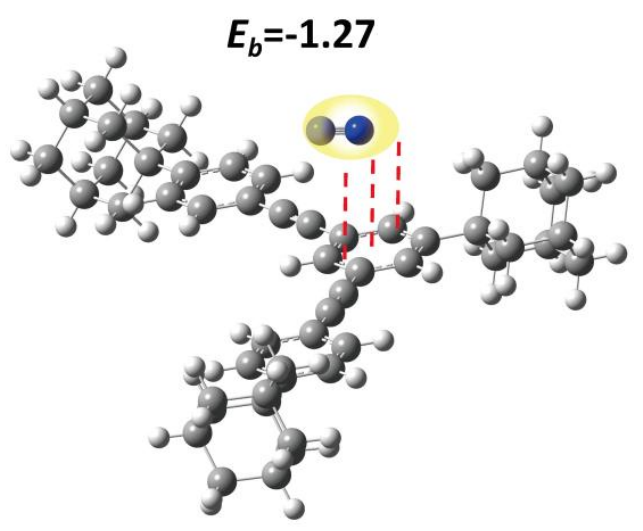

Figure S17. Calculated binding sites and binding energies $\left(E_{b}\right.$ in $\left.\mathrm{kcal} \mathrm{mol}^{-1}\right)$ of $\mathrm{N}_{2}$ located above the phenyl rings of the fully optimized MPOF-Ad-1 (a), MPOF-Ad-2 (b) and MPOF-Ad-3 (c).

Table S6. Calculated binding energies between the adsorbed small gases $\left(\mathrm{CO}_{2}, \mathrm{CH}_{4}, \mathrm{~N}_{2}\right)$ and the MPOF-Ads networks

\begin{tabular}{ccccc}
\hline \multirow{4}{*}{ Samples } & \multicolumn{4}{c}{$E_{b}\left(\mathrm{kcal} \mathrm{mol}^{-1}\right)$} \\
\cline { 2 - 5 } & $\mathrm{CO}_{2}{ }^{\mathrm{a}}$ & $\mathrm{CO}_{2}{ }^{\mathrm{b}}$ & $\mathrm{CH}_{4}{ }^{\mathrm{a}}$ & $\mathrm{N}_{2}{ }^{\mathrm{a}}$ \\
\hline MPOF-Ad-1 & -3.88 & -2.46 & -0.96 & -1.46 \\
MPOF-Ad-2 & -3.44 & -2.03 & -0.84 & -1.24 \\
MPOF-Ad-3 & -3.69 & -2.58 & -0.86 & -1.27 \\
\hline
\end{tabular}

${ }^{a}$ The adsorbed small gases located right above the phenyl rings on the fully optimized MPOF-Ads geometries

b The adsorbed small gases located on the lateral of the phenyl rings on the fully optimized MPOF-Ads geometries 


\section{Thermodynamic factors for gases}

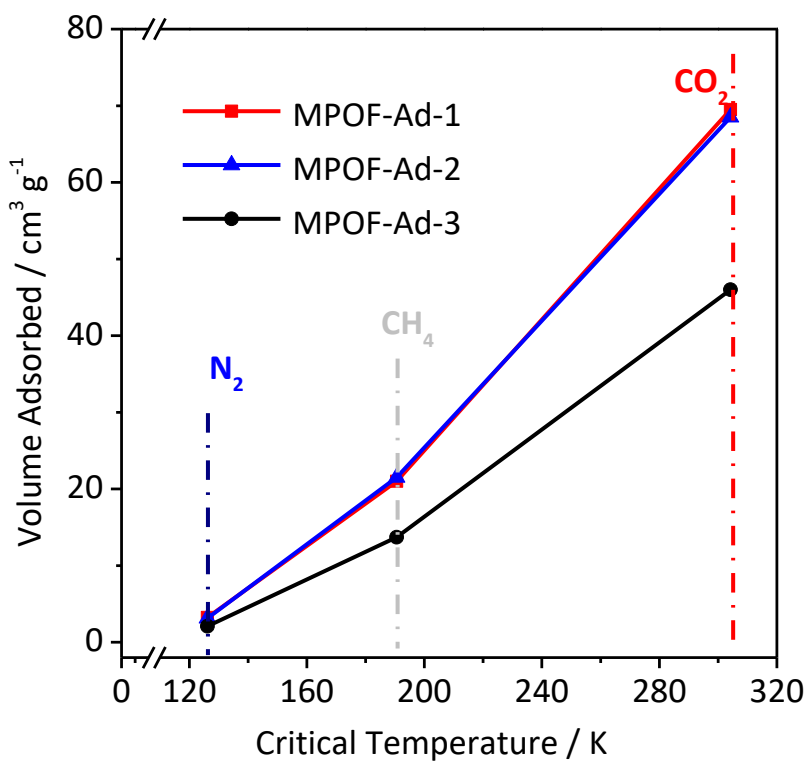

Figure S18. Dependencies of gas uptake capacity of MPOF-Ad-1 (red), MPOF-Ad-2 (blue) and MPOF-Ad-3 (black) on the critical temperature of three gases.

\section{Supporting references}

(S1) Jiang, W. Z.; Yue, H. B.; Shuttleworth, P. S.; Xie, P.; Li, S. J.; Guo, J. W. Adamantane-Based Micro- and Ultra-Microporous Frameworks for Efficient Small Gas and Toxic Organic Vapor Adsorption. Polymers 2019, 11 (3), 486.

(S2) Yang, K.; Guo, J. W. Three-Dimensional Nanoporous Organic Frameworks Based on Rigid Unites. Mater. Lett. 2019, 236, 155-158.

(S3) Song, J. R.; Duan, W. G.; Li, D. P. Synthesis of Nitrogen-Rich Polymers by Click Polymerization Reaction and Gas Sorption Property. Molecules 2018, 23 (7), 1732.

(S4) Wang, X.; Zhao, Y.; Wei, L.; Zhang, C.; Jiang, J.-X. Nitrogen-Rich Conjugated Microporous Polymers: Impact of Building Blocks on Porosity and Gas Adsorption. J. Mater. Chem. A 2015, 3 (42), 21185-21193.

(S5) Xu, Y.; Chang, D.; Feng, S.; Zhang, C.; Jiang, J.-X. BODIPY-Containing Porous 
Organic Polymers for Gas Adsorption. New J. Chem. 2016, 40 (11), 9415-9423.

(S6) Chen, D. Y.; Fu, Y.; Yu, W. G.; Yu, G. P.; Pan, C. Y. Versatile Adamantane-Based Porous Polymers with Enhanced Microporosity for Efficient $\mathrm{CO}_{2}$ Capture and Iodine Removal. Chem. Eng. J. 2018, 334, 900-906.

(S7) Kundu, S. K.; Bhaumik, A. Novel Nitrogen and Sulfur Rich Hyper-Cross-Linked Microporous Poly-Triazine-Thiophene Copolymer for Superior $\mathrm{CO}_{2}$ Capture. ACS Sustainable Chem. Eng. 2016, 4 (7), 3697-3703.

(S8) Jin, T.; Xiong, Y.; Zhu, X.; Tian, Z.; Tao, D. J.; Hu, J.; Jiang, D. E.; Wang, H.; Liu, H.; Dai, S. Rational Design and Synthesis of A Porous, Task-Specific Polycarbazole for Efficient $\mathrm{CO}_{2}$ Capture. Chem. Commun. 2016, 52 (24), 4454-4457.

(S9) Wu, Y.; Wang, J. X.; Muhammad, Y.; Subhan, S.; Zhang, Y. B.; Ling, Y.; Li, J.; Zhao, Z. X.; Zhao, Z. X. Pyrrolic N-Enriched Carbon Fabricated from Dopamine-Melamine via Fast Mechanochemical Copolymerization for Highly Selective Separation of $\mathrm{CO}_{2}$ from $\mathrm{CO}_{2} / \mathrm{N}_{2}$. Chem. Eng. J. 2018, 349, 92-100.

(S10) Das, S. K.; Bhanja, P.; Kundu, S. K.; Mondal, S.; Bhaumik, A. Role of Surface Phenolic-OH Groups in N-Rich Porous Organic Polymers for Enhancing the $\mathrm{CO}_{2}$ Uptake and $\mathrm{CO}_{2} / \mathrm{N}_{2}$ Selectivity: Experimental and Computational Studies. ACS Appl. Mater. Interfaces 2018, 10 (28), 23813-23824.

(S11) Frisch, M. J.; Trucks, G. W.; Schlegel, H. B.; Scuseria, G. E.; Robb, M. A.; Cheeseman, J. R.; Scalmani, G.; Barone, V.; Mennucci, B.; Petersson, G. A.; Nakatsuji, H.; Caricato, M.; Li, X.; Hratchian, H. P.; Izmaylov, A. F.; Bloino, J.; Zheng, G.; Sonnenberg, J. L.; Hada, M.; Ehara, M.; Toyota, K.; Fukuda, R.; 
Hasegawa, J.; Ishida, M.; Nakajima, T.; Honda, Y.; Kitao, O.; Nakai, H.; Vreven, T.; Montgomery, J. A.; Jr.; Peralta, J. E.; Ogliaro, F.; Bearpark, M.; Heyd, J. J.; Brothers, E.; Kudin, K. N.; Staroverov, V. N.; Keith, T.; Kobayashi, R.; Normand, J.; Raghavachari, K.; Rendell, A.; Burant, J. C.; Iyengar, S. S.; Tomasi, J.; Cossi, M.; Rega, N.; Millam, J. M.; Klene, M.; Knox, J. E.; Cross, J. B.; Bakken, V.; Adamo, C.; Jaramillo, J.; Gomperts, R.; Stratmann, R. E.; Yazyev, O.; Austin, A. J.; Cammi, R.; Pomelli, C.; Ochterski, J. W.; Martin, R. L.; Morokuma, K.; Zakrzewski, V. G.; Voth, G. A.; Salvador, P.; Dannenberg, J. J.; Dapprich, S.; Daniels, A. D.; Farkas, O.; Foresman, J. B.; Ortiz, J. V.; Cioslowski, J.; Fox, D. J. Gaussian 09, Revision D.01,, Gaussian, Inc.: Wallingford CT, 2013. 